\title{
Problematic Issues of Goal Setting and Optimization in the Development of the Russian Transport Complex
}

\author{
Vladimir A. Persianov ${ }^{1}$, Alexey M. Lyalin ${ }^{2, *}$, Anna V. Kurbatova ${ }^{1}$, Tatyana N. \\ Eremina $^{3}$
}

\author{
${ }^{1}$ Department of Management of Transport Complexes, Institute of Industrial Management, State University of \\ Management, Moscow, Russia \\ ${ }^{2}$ Department of Project Management, Institute of Industrial Management, State University of Management, Moscow, \\ Russia \\ ${ }^{3}$ Department of International manufacturing business, Institute of Industrial Management, State University of \\ Management, Moscow, Russia \\ *Corresponding author. Email: kaf_up@guu.ru
}

\begin{abstract}
The introductory part of the article shows that modern transport is one of the main conditions for successful solution of urgent social, economic and political problems, including national security of the country. The disintegration of the transport system during the years of market reforms has complicated the management of transport flows and reduced the efficiency of using transport production capacity. Market reforms have significantly changed the working conditions of transport and the distribution of transport between its various types. Transport has lost its organizational and managerial integrity and has ceased to operate as a single production and technological complex. First, this applies to Railways. The load capacity of many railway lines has decreased, the turnover of the car fleet has slowed down, and transportation tariffs have increased.

The article attempts to consider several issues related to improving the efficiency of management of the country's transport complex in the context of the transition to the digital economy. Two groups of problematic issues are considered in detail: the first group - goal setting in projects and programs for the development of transport infrastructure and the organization of transport flows; the second groupoptimization of design and planning solutions for the development of transport by the criterion of minimum costs using economic, mathematical and instrumental research methods.

The problematic issues of the first group are proposed to be solved based on the requirements of systematic and proportional development of all elements of the transport complex of the country (region, municipality). Vector algebra is used as a tool for quantitative (digital) estimation to obtain an integral indicator. The calculations consider deviations of the vector of the actual state of the transport complex from the required (target, normative) state not only in size, but also in direction. This allows the developed transport development projects to consider both the requirements of uniformity and proportionality.

On the second group of issues, the article reveals the difficulties of objectively digital assessment of design and planning solutions for the development of transport using linear, parametric, stochastic, and other types of programming. The paper shows the disadvantages of a formal and logical approach to optimizing projects and programs for the development of transport complexes based on one (most often-cost) criterion, without taking into account other factors.

In the final part of the article, the requirements for state control and goal setting in the field of transport are formulated.
\end{abstract}

Keywords: organization, management, technology, interaction, goal setting, optimization, control 


\section{INTRODUCTION}

The transport network has been serving the production infrastructure of the national economy of Russia for many years, being one of the main parts of this conglomerate. Today, transport continues to largely determine the socioeconomic development of the country as a whole and its individual regions. One of the goals of public administration in modern conditions is to improve the welfare of the population. To achieve these goals, the latest management methods are used, a clear example of which is the transition to priority national projects. Putin signed a decree (2018), which reflects the thirteen national objectives, including Infrastructure project [1]. Transport is assigned to provide basic living conditions for citizens of the country, which will be achieved by the introduction of high-speed container transport in the Russian Federation. However, the goal is impossible without solving foreign policy problems, including the national security of the country.

By the beginning of the 90s of the last century, Russia had developed a Mature transport infrastructure that created conditions for internal economic relations between regions, increased the mobility of the population, and allowed it to meet the needs of the country's foreign trade. However, even in those years, the transport complex did not always provide full and timely satisfaction of the needs of the economy and the population in transportation. The disintegration of the country's transport system during the years of market reforms has further complicated the management of transport flows.

\section{METHODOLOGY}

The object of the research is railway transport as part of transport communications in Russia, and the subject is economic policy and the choice of strategic guidelines for innovative development at the final stage of market reforms.

Scientific novelty of research consists in development of theoretical provisions and methodological approaches, we see the need and possibility of increasing the efficiency of organizational and economic reforms in railway transport on the basis of the analysis of the objective trends of the socio-economic development of the country and requirements for ensuring its national and economic security.

We show the feasibility of switching from a predominantly organizational and managerial trajectory of transformation to a predominantly innovative and technological trajectory with bifurcation in the coming years. We offer quantitative tools for managing changes in the industry using the ideology and mechanisms of project management.

The methodological basis of the research is a systematic approach to the industry - considering it as a single production and technological complex, parts of which are interconnected and in a state of dynamic equilibrium. Specific economic analysis is supplemented by mathematical modeling and experimental calculations. The paper uses legal acts and target programs of the Russian Federation, statistical data of the Federal state statistics service and JSC "Russian Railways", works of domestic and foreign scientists, research and design organizations, transport universities.

\section{RESULTS AND DISCUSSION}

Transportation management and optimization issues have become problematic.

\subsection{Situation analysis}

The experience of the last decade shows that the restructuring of the country's transport sector has not produced the expected results. According to experts, the Concept of state transport policy approved by the Government of the Russian Federation (1997) has partially lost its relevance due to low efficiency. This goal was realized during the crisis period of the country's economic growth. Many operational and economic indicators of transportation activities were deteriorating. In General, the demand for transport services is being met, but today transport is not just required to meet demand. The main factors determining its development are strategic guidelines - national socio-economic priorities and national interests, while the structure-forming and stabilizing role of transport increases significantly [2].

First of all, this applies to the railway sector, which has lost its organizational and managerial integrity as a result of the reforms and has ceased to operate as a single production and technological complex. In 2004, the Ministry of Railways of the Russian Federation was liquidated. Formed in 1865, it successfully managed the management of the industry in both tsarist and Soviet Russia, ensuring the implementation of state transport policy, the development of targeted programs in the field of transport, transport engineering and transport construction; actively solved the strategic tasks of individual sectors of the economy and the national economic complex as a whole, using the existing infrastructure of the transport system. Automobile, sea, river, and air transport were subjected to even greater disintegration [3, 4].

In January 2010, a round table of The State Duma will discuss the results of previously adopted market reforms that affect the infrastructure of the transport system, including rail transport. The conclusions reached during this meeting are reflected in the recommendations for the Russian Government:

- accelerate the formation of a competitive market for freight cars by allocating the inventory fleet of JSC "Russian Railways" to JSC " Second cargo company»; 
- provide passenger transportation using the mechanism of state order under the Federal budget for suburban transport, achieving a break-even level of suburban passenger transport;

- approve the legal framework for the "network contract" mechanism within the framework of the state subsidy system;

- develop a model for setting goals for the railway transport market in accordance With the strategy for the development of railway transport in the Russian Federation until 2030;

- prepare amendments to the main Federal laws regulating railway transport [4].

Over the past decade, many of these recommendations have been implemented. According to the results of the analysis, Russian Railways has about 200 subsidiaries. Today, the process of splitting is actively continuing, and the level of the $50 \%$ threshold for the share of the authorized capital owned by the company is alarming [5].

The system of public administration, including social management, is directly related to the practical resolution of issues affecting the interests of society as a whole. Railway reforms (2006-2010) led to a radical organizational and managerial transformation of the transport industry infrastructure.

Federal passenger Directorate (2005), United dozens of road and regional directorates as an independent company. The organizational structure of the company absorbed fifty car depots, which numbered thousands of passenger cars and other state property.

The process of" dividing the whole into parts", reflected in the fragmentation of the passenger complex on the Railways, continued and was characterized by an increase in the number of companies for suburban passenger transport, which was approaching three dozen. This later led to the creation of the railway station Management, which wants independence. The emergence of a "new" management structure is accompanied by the allocation of "new" criteria for the classification of existing stations. "Selected" stations operate normally, serving about $85 \%$ of passengers traveling on long-distance trains, from the total passenger traffic. "Unpromising" railway stations (about 4 thousand) are waiting for the decision of the company's management Board, which may result in closing, re-profiling, leasing, etc. After all, the process of" decomposition " of the passenger economy has already affected each individual station with the separation of ticket offices, waiting rooms, storage rooms, etc.

Concrete steps to achieve the railway transport development Strategy did not lead to mitigation of the consequences of the crisis phenomena of reforming the transport industry infrastructure. However, significant risk components in this goal setting are that the decisions made did not take into account the interests of the country in terms of geopolitical and geo-economic aspects, historical experience was left without due attention, there was no consideration of national characteristics of the Russian economy, there were no detailed feasibility studies, methods and tools of project management were not used, etc. The above list of unsatisfied state of transport infrastructure in Russia is very similar to the "black box" theory, when the settlement is carried out by the methods of "similarity and analogy", "trial and error", and the prototype of the applied model is based on theoretical knowledge taken from foreign practices, sometimes not the most successful for the implementation of national priority projects of the Russian Federation.

Today, the reasons for inefficient implementation of transport sector reform have been identified. The identified discrepancies require a broad inventory of the entire material and technical base of transport. The low efficiency of management decisions is organizational in nature: the lack of necessary professional education, which leads to the inability to work in the new conditions of digitalization of the economy; inefficient technical equipment that hinders the work of specialists of all transport infrastructure services, lack of proper competition taking into account the entire complex of production, economic, social, environmental and other requirements of the modern market [6].

The Russian business community is fundamentally building its business activities in accordance with Industry 4.0 standards. to manage and implement this concept, it is necessary to fully implement all stages of the state program for the development of the digital economy. Today, the electronic economy integrates all the variability of the country's economic activity. The main concept of Industry 4.0 is to build an ecosystem of the digital economy. The authors recreate the concept of digital (electronic) economy as developing on the basis of basic economic laws in the conditions of intensification of the use of digital technologies in production and management [7].

Integration of this task is also practically feasible for the transport industry. Even the lack of a proper reliable information base, the lack of readiness of employees of subsidiaries to make effective management decisions, and a weak vision of the future mode of transport are not able to stop the modernization and building of the ecosystem of the country's transport complex. There is no doubt that the work done within the framework of the Infrastructure project, supplemented by scientific expertise, methods and tools of project management, the creation of organizational structures capable of coordinating the ecosystem's relationships, such as project offices, will provide an opportunity to start solving the most important task - setting goals (strategic guidelines) for the transport complex of Russia.

\subsection{The problem of goal setting}

Almost three decades ago, our country-the Union of Soviet Socialist Republics (USSR) - in the person of its leaders rejected the course of socialism adopted in 1917, that is, the construction of a new social formation, whose 
citizens have a common goal; they solve a common task to build a just society, the motto of which was to become the formula: "from each - according to ability, to each according to labor!"; they do "a common cause", guided by a clear goal setting, centralized state planning, management and control.

The alternative to socialism was a return to the past - a "market economy", that is, capitalism, with the rule of private ownership of the means of production. The goal of production under capitalism was and still is maximum profit. According to Marx, for example, "there is no crime that capital would not risk, even on pain of the gallows" [8]. Capitalism by its very nature is repugnant to our culture and traditions, it is quite satisfied with the ignorance and semi-education of school and University graduates, as the candidate of Sciences O. Chetverikova rightly says today [9]. And we see from our own experience what this leads to in all spheres of human activity, not only in our country, but also abroad.

We must admit that after decades of breaking down the Soviet economy and our entire social order, including education, health, culture and science, there is virtually no hope for a better, happier future. And where will this better future come from for a consumer society, each member of which is brought up from childhood in the spirit of confrontation, competition with their own kind only for money, material goods and power, and is guided by animal instincts? And our (supposedly free of ideology), the state is not going to educate (to give light, justice, knowledge, and understanding of the world), does not seek to "humanize" the younger generation, and outlines the transition in higher education from "knowledge" paradigm to the "activity" approach independent "free" issues and challenges in their professional orientation. In other words, the younger generation develops fighting qualities, the ability to stay ahead of competitors, implementing their business projects, desires, etc., while demonstrating not the potential of their knowledge, but wild anti-human qualities.

This is very well stated in the works of the doctor of physical and mathematical Sciences of the Center for scientific political thought and ideology, S. S. Sulakshin, who suggests that a person dreams about the future not in order to predict it. A thinking person plans to change their fate, karma, etc.for the better. This distinguishes us from the animal, because goal-setting is one of the main characteristics of a person. Realizing the uniqueness and value of the goal, the individual goes to it. The most important aspect is truth, which confirms that the goal does not go beyond consumption and existence. Goal setting for the future is always based on current achievements, but taking into account dissatisfaction with the present. In His scientific works S. S. Sulakshin asks three questions:

- Why and what is unsatisfactory?

- How and what should be changed?

- How to get to the planned new state? [10].
If we consider the proposed theory as steps to action, then answering the questions asked, we can touch on any branch of the country's economy, including transport, metallurgy, mechanical engineering, construction and the national economy as a whole.

The investment policy that production is focused on is of great (if not decisive) state significance for us today. March 2020 introduced significant changes in the process of financing national projects. The state budget sequestered a number of expenditures, which led to a 5\% reduction in expenditures from the entire budget for the implementation of national priority projects. This fact will entail more stringent co-financing requirements for regional budgets. I would particularly like to note the risk that the initial goal will not be realized (or significantly changed) due to adjustments not only to co-financing of the national welfare Fund and regional budgets, but also due to the lack of appropriate organizational infrastructure, including transport [11].

The digital transition brings comprehensive changes to production as well as social processes, which additionally cover the replacement of organizational structures of companies and business processes. A number of possibilities are put forward to achieve conscious goalsetting. The authors suggest using the vector method, which allows reducing economic risks to minimum values due to the objectivity and meaningfulness of the production culture.

The proposed method is based on a mathematical model, where the components of vectors are expressed in relative values. All assumed component elements of the goal vector are assumed to be equal to one. The effectiveness of the management decision depends on the maximum convergence of vectors, which are considered in the model as a comprehensive characteristic of the object.

In order to quantify the degree of convergence of vectors, it is proposed to introduce a coefficient calculated by the formula with the coefficient of the degree of convergence of vectors of the object to the goal; the length of the vector that characterizes the object's state; the length of the target (strategic) vector [1].

If we consider the General trends in the transport industry, the model shows that these vectors are not equal. The state of the transport industry significantly affects their divergence in size (length) and direction. The model allows us to characterize the degree of approximation of the object to the goal, which is reflected in the calculations of the cosine of the angle.

The main limitation of this method is that it is not allowed to use less than two components for the calculation, since multi-aspect goal setting will not be achieved, due to the conversion of vectors into scalar values.

Each model generates positive aspects from application in practice and allows you to identify common trends. This statement was confirmed for the vector method in the following positions:

* expression of strategies (goal setting) of an object with quantitative components; 
* representation of the variable aspects of the object's activity to comparable values;

* calculation of the effectiveness of organizational management of the object without uncertain and uncontrolled indicators;

* making conscious management decisions in a constantly changing environment, taking into account complex indicators.

The revealed General trends of the method are typical for any current moment of the company's production activity, including companies in the transport industry. The functional interconnection with other transport infrastructure objects is significantly expanded, which makes it possible to detect lagging links in the transport network, etc.

When using the classical vector method, there is no set of variations. However, digital transformation allows you to significantly expand the components of vectors that characterize all the main directions of the company's production activities on the one hand, and the target (strategic) indicators, on the other hand. To be effective, it is necessary to replace analog devices with digital ones, which will create an ecosystem of modern transport infrastructure.

The concept of goal management is quite popular for Russian companies, where setting goals is regulated by management. Digitalization of managers ' activities is faced with a lack of formalized data. The development and implementation of business processes clearly set the requirements for knowledge of analytical indicators of the subject area. In creating a modern effective model of management processes, it is important to use the vector method, which allows us to take into account the significance of the developed vector components for a specific situation by introducing scale (weight) coefficients into calculations.

The presented vector method helps to preserve the basic proportions in the structure of the object and forms an integral digital platform, which is an integral part of the essence of the goal-setting mechanism. Goal attainment within the framework of operational modernization of business processes can be applied to any production facility of the transport system [12, 13].

Digital transformation is aimed not only at the commercial component of transport development, but also at the new content of business process integration. Significant transformation of organizational management structures using flexible technologies, cloud computing, and big data, as well as reasonable use of existing methods of economic calculations, will make them comprehensive for the implementation of the infrastructure targets of the national priority project.

\subsection{How to understand the optimization}

In transport, various economic-mathematical and instrumental methods are traditionally used to solve optimization problems [14]. Computer modeling is widely used. In the middle of the last century, linear programming methods were preferred. Positioning in linear programming problems was based on the range of acceptable values of variables. From the very beginning, we note that the novelty of this method is very relative. Already the works of Lamet and Clapeyron (the beginning of the XX century) can be interpreted in the spirit of linear programming problems. Subsequently, tasks of this kind were handled by the German Foppl, and in our country ing. Jacyna, member of the Academy Shevyakov and other scientists.

In the educational process, the nature of linear programming was widely used to solve the "transport problem", where the main goal was to minimize transportation costs. The quantity of cargo (xij), departure points (i), and destination points (j) were initially set in the condition of the transport problem to be solved, and the trainee had to attach suppliers to consumers in such a way that the total cost of transportation was the lowest.

The difficulty of practical implementation is to achieve an extreme value for a linear function at the boundary of the domain where partial derivatives do not exist. This allows you to get the values of the desired values xij, which are responsible for the best reduction in the cost of transportation, even though the transport conditions themselves were not affected. If, for all other unchanged positions, only the transport conditions have changed, the calculated optimum will be false.

The theoretical basis of the classical solution method allows us to take into account new conditions that will lead to a new optimum. But linear programming in this case reflects the optimum of the static state, and practice requires the optimum of the change process. The logistics of traffic management will not immediately be able to redistribute the attachment of suppliers to consumers from the first optimum to the second.

The process of non-linearity of most transport problems is confirmed in the calculation of the cost of transportation (Cij), which changes with the change of xij. The failure of the optimization criterion itself is compounded by the lack of consideration for quality transport link.

The government of the Russian Federation is optimizing the structure of the economy from the perspective of Industry 4.0. to integrate Cyber-Physical System (CPS) into the business processes of transport, a digital enterprise horizontal is required, which reflects all stakeholders in the value chain. Today, the digital economy combines all the variety of methods of mathematical, integer, parametric, stochastic programming, etc. Creating a digital enterprise ecosystem is not possible without a vertical, which is characterized by production, logistics, operation, etc.

Each programming method is designed for a specific range of tasks. For example, integer programming uses variables with a limited number of discrete values. An example of a typical task in the educational process "on the distribution of personnel", which has only integers in 
the answer, reflects a static process, does not consider psychosomatic features of personal development at all. Dynamic development of processes is poorly reflected in parametric programming. Here the emphasis is placed on considering variations of individual parameters of the problem within certain limits. But stochastic programming generally excludes any significant goal setting in the processes of traffic flow management.

The main state task in the development of the digital economy is to create an ecosystem of a digital enterprise that is based on an integrated digital platform. This will allow you to use mathematical regularities for digital programming taking into account the dynamic process. The main advantage of using digital technologies will be the rejection of dead frozen forms, where the internal structure of" moving " elements remains unchanged [15]. From the above analysis of mathematical tools, it follows: the language of mathematics often provides us with great help, but it can not replace the method itself, which is determined by the nature of the object under study and depends on the researcher's worldview, which decides to be essential, meaningful (dialectical) or abstract, formally logical. Mathematics in economic research on transport has played and will continue to play an important but auxiliary role, and in this respect, there can be no two points of view. It is possible to speak about mathematical methods of optimal solution of real transport problems only with big reservations.

Any model, including mathematical one, considers an elementary object placed in a reference environment that is alien to the nature of biological systems. This was also shown by D. I. Blokhintsev in classical mechanics that the dependence (F) can very imperfectly reflect real production processes. A train in real traffic conditions cannot reflect only one single variable $\mathrm{x}$, which in the considered dependence characterizes the weight of the train.

The realities of life contribute to $y=F(x)$ for the case when $\mathrm{x}$ is the weight of the train and $\mathrm{y}$ is the operating cost, $\mathrm{a}$ multi - sided set of dependencies. These variables can be either continuous or discrete, which makes it impossible to predict their changes over time. The complexity of using a set of dependencies in time is limited by the dependence that corresponds to the real conditions of the object's development, in each particular case, with justification for the permissibility of such mathematical manipulations and transformations.

I would like to touch on the real meaning of the function $\mathrm{y}=\mathrm{F}(\mathrm{x})$ for most tasks related to production systems. For an example of the transport industry, consider the capacity of the station. The material content of the proposed production system will also include a qualitative aspect, which will be reflected in the adopted scheme of their mutual connection, grouping in parks, order of use, etc.

The above requires a return to meaningful analysis based on the principle of "concrete analysis of a specific situation".
The reader may ask whether it is worth talking so much about the application of mathematics to economic research. Our answer is worth it. When Helvetius declared man a machine in the eighteenth century, few people cared. The peasants worked the nobles could hunt and amornchai, wrote poetry... Theories must be handled carefully these days. An incorrect theory can permanently disorganize practice and lead to huge material costs. In the relations between theory and practice, mathematics and concrete Economics, there must be a measure, and, apparently, not formally logical, but more meaningful.

The preference for the use of digital technologies is shown in the high reliability of analytical data that allow the transport industry to understand the concept of "optimization"in a new way. Many representatives of the scientific community continue to rely on a systematic approach, which will also allow us to define optimization in a new way [16-18]. Analysis of literature sources has shown that the works trace a new understanding of the essence of optimization, expressed in the following provisions [10].

First. Irreducibility of one quality to another by means of a quantitative measure (structure to function and Vice versa). This provision is based on the rejection of assumptions in the developed models "all other things being equal". This step will allow you to qualitatively change the output parameters of the model considering the actual developing environment through a more effective comparative analysis of management decisions.

Second. Recognition of the objective conditionality of the development process. This statement allows us to ignore the illusion of multiple variations, which presupposes unlimited "free will". The existing restriction of choice is due to ideological, national, political, ideological and other considerations of society. The main difficulty in choosing the optimal option is to justify the only correct solution in this case.

The third. Rejection of traditional ideas about the optimality criteria. This provision radically changes the attitude to management and gives it a dominant role. In his book, V. I. Tereshchenko wrote that the determining factor is the managerial moment. It is not the theoretical optimality in the use of machines, materials, etc. that sets the limit, but the practical possibility of" covering " this type of activity by management [19].

W. Ross Ashby considered system optimization as the achievement by an organism of such a state or value that lies within the specified limits [20]. The use of forward and feedback loops often becomes of little use in optimization tasks. The guarantee of the optimal design solution is the confidence that it is feasible and allows you to operate the object in the highest performance mode.

According to I. V. Belov, the optimality criterion can only be natural, expressed in an increase in the productive power of the transport system [12]. This criterion is not used in the existing methods for calculating transport performance assessment. 


\section{CONCLUSION}

Improving the efficiency and development of the transport complex of the Russian Federation is impossible without restoring the industrial and technological integrity of the industry and increasing the role of clear state goal-setting and control in the management of the industry. The priority practical tasks are:

* centralized planning with state control of market competition and the introduction of private business in the public interest;

* maintaining state ownership in the basic sectors of the economy, which should include transport, energy and military-industrial enterprises;

* orientation and goal-setting in the activities of various social groups and professional communities in non-basic sectors of the economy for the growth of public welfare; * state control of pricing in basic sectors of the economy. The entire system of state regulation and control of the Russian economy, including transport, should be aimed at producing consumer goods and improving the quality of life of the population [21]. In all types of business, including public-private partnerships, the moral principles and norms of responsible entrepreneurship and the protection of public interests should be present and strengthened.

\section{REFERENCES}

[1] A. Lyalin, A. Zozulya, T. Eremina, P. Zozulya, N. Malyshkin, Efficiency issues for managing priority national projects, in: Materials of the international scientific conference "Man-Power-Law-Governance: Interdisciplinary Approaches", Atlantis Press, 2019, vol. 374. DOI: https://doi.org/10.2991/mplg-ia19.2019 .77

[2] T.M. Gainochenko, A.V. Kurbatova, E.S. Kurbatova, Key Parameters of Transport Development in Russia at the Contemporary Stage, in: A. Bogoviz, Y. Ragulina (Eds.), Industry Competitiveness: Digitalization, Management, and Integration, Lecture Notes in Networks and Systems, vol. 115, Springer. DOI: https://doi.org/10.1007/978-3-030-40749-0_4

[3] P. Kurenkov, O. Pokrovskaya, M. Anastasov, M. Sokolov, A. Bochkov, Study of the current state of the transport infrastructure of road and rail transport of the Russian Federation, in: IOP Conf. Ser.: Mater. Sci. Eng., 2019, vol. 698. I. 6. DOI:10.1088/1757899X/698/6/066064

[4] A.O. Merenkov, Scientific thought in the development of transport in Russia: a historical retrospective, problematic issues and strategic guidelines.: a monograph. Moscow, Translit publishing house, 2019, $496 \mathrm{p}$.

[5] V. Persianov, E. Rudakova, A. Safronova, A. Semenova, N. Pilipchuk, Trends in the Development of Corporate Ethics in the Company "DHL" and JSC "Russian Railways" in the Current Socio-Economic Conditions, in: Z. Popovic, A. Manakov, V. Breskich (Eds.), VIII International Scientific Siberian Transport Forum, TransSiberia, 2019, Advances in Intelligent Systems and Computing, vol. 1116, pp. 657-671. DOI: 10.1007/978-3-030-37919-3_66

[6] A.V. Kurbatova, Traffic flow management in terms of Informatization of the transportation process, Ref. diss. doct. econ. Science, Moscow, 2000, 62 p.

[7] K. Marx, F. Engels, Capital. Criticism of political economy. Volume 1. Book I: The process of capital production, Works. Second edition, State Publishing House of Political Literature, 1960.

[8] T.N. Eremina, A.I. Evseeva, A.M. Lyalin, Process approach as a prerequisite for the digital transformation of enterprises, in: Materials of the 2nd International scientific forum "Step into the future: artificial intelligence and digital economy", Moscow, GUU, 2018, Iss. 3, pp. 181-192.

[9] O.N. Chetverikova, Transhumanism in Russian education. Our children as a commodity, Knizhnyy mir, 2018

[10] S.S. Sulakshin, The image of the future of Russia, in: Proceedings of the Center for scientific political thought and ideology, 2015, vol. 10, Moscow, Nauka i politika, $32 \mathrm{p}$.

[11] A.V. Kolesnikov, N.S. Stepanov, E.Y. Kamchatova, L.E. Zernova, E.V. Korolyuk, G.G. Verbina, A.B. Zelinskaya, Long term forecast and programming of financing of internal costs of the innovation and investment sector of the Russian Federation, Religación. Revista De Ciencias Sociales $Y$ Humanidades 4(18) (2019) 154-162.

[12] I.V. Belov, V.A. Persianov, Economic theory of transport in the USSR: historical experience, modern problems and solutions, a look into the future, Transport, 1993.

[13] V.A. Persianov, K.Yu. Skalov, N.S. Uskov, Modeling of transport systems, Transport, 1972. 
[14] O. Pokrovskaya, R. Fedorenko, Assessment of Transport and Storage Systems, in: Z. Popovic, A. Manakov, V. Breskich (Eds.), VIII International Scientific Siberian Transport Forum, TransSiberia 2019, Advances in Intelligent Systems and Computing, vol. 1115 , pp. 570-577. DOI:10.1007/978-3-03037916-2_55

[15] F. Polese, A. Botti, A. Monda, M. Grimaldi, Smart City as a Service System: A Framework to Improve Smart Service Management, Journal of Service Science and Management 12 (2019) 1-16. DOI: $10.4236 /$ jssm.2019.121001

[16] T.M. Gainochenko, Social and economic power as a regulator mechanism of self-organization transport system, in: Proceedings of 2017 10th International Conference Management of Large-Scale System Development, 2017, DOI:

10.1109/MLSD.2017.8109622

[17] A. Kurbatova, P. Kurenkov, A. Safronova, I. Tanaino, Selection of optimal supply schemes, IOP Conf. Ser.: Earth Environ. Sci., 2019, vol. 403, DOI:10.1088/1755-1315/403/1/012231

[18] M. Dedík, T. Čechovič, J. Gašparík, J. Majerčák, Rationalization of the passenger transport system as an important transport system. Transportation Research Procedia, 13th International Scientific Conference on Sustainable, Modern and Safe Transport, TRANSCOM 2019, vol. 40, pp. 193-200. DOI: https://doi.org/10.1016/j.trpro.2019.07.030

[19] V.I. Tereshchenko, Organization and management (the experience of the United States), Ekonomika, 1965.

[20] W.R. Ashby, An Introduction to Cybernetics, Martino Publishing, 2015.

[21] T.N. Sakuleva, The MAAS System and its problems, E-Management 1,2 (2018) 30-37. DOI: 10.26425/2658-3445-2018-2-30-37 